\title{
Focus on osteo-ligamentous injuries around the ankle
}

\author{
T. Mittlmeier ${ }^{1}$
}

Received: 5 October 2015 / Accepted: 17 October 2015 / Published online: 6 November 2015

(C) Springer-Verlag Berlin Heidelberg 2015

Ankle fractures and ligamentous injuries at the lateral ankle are among the blockbusters in trauma of the lower leg [1]. The intermediate and long-term outcome with around $10 \%$ of patients with symptomatic osteoarthritis is not that good as often presumed [2]. Despite the ubiquitous high incidence of malleolar fractures and in knowledge of the fact that with increasing number of the involved malleoli, in particular, of the posterior ankle and the need for placing a positioning screw, the prognosis is getting worse and evidence-based recommendations for treatment are lacking [1, 3-5]. Presence of fracture dislocation at injury, articular surface congruity and residual talar subluxation are obviously relevant prognostic parameters [3]. Of course, the mantra of anatomical and functional restoration of any particular lesion may represent our general guideline for treatment of ankle fractures, but, it does hardly substitute the need for prospective multicentre studies to clarify the prognostic value of fragment size which has been regarded as a relevant parameter for decision making in refixation of posterior malleolar fractures for decades [3, 4].

Bartoníček et al. [6] supply us a with a new classification of posterior malleolar fragment which relies on preoperative CT analysis of the ankle joint and has clinical implications regarding the need for fragment refixation and the optimized selection of the surgical approach. Rammelt et al. [7] underscore that syndesmotic disruptions are frequently associated with bony avulsions or malleolar fractures which make anatomic reduction within the incisura necessary. Malreduction is one of the major risks in these

T. Mittlmeier

thomas.mittlmeier@med.uni-rostock.de

1 Department of Trauma, Hand and Reconstructive Surgery, Rostock University Medical Center, Rostock, Germany patients which should be ruled out by intraoperative $3 \mathrm{D}$ fluoroscopy or postoperative CT scan to avoid long term complications.

Our actual focus is not limited to the most frequent ankle lesions, but refers to further entities of ankle trauma which may be under diagnosed or underreported [8, 9].

Lötscher et al. [10] concentrate on the various types of injuries on the medial side of the ankle joint which range from ligamentous injuries to fractures or combination injuries. Missed injuries bear an inherent risk of poor outcome. Thus, adequate diagnosis and selection of treatment is decisive. Mittlmeier et al. [11] address acute and chronic subtalar joint instability which is easily misinterpreted as a ligamentous injury of the ankle joint and might result in complaints due to chronic instability. Chronic subtalar joint instability is still a topic with quite heterogeneous proposals for surgical treatment despite promising short-term outcome of various techniques.

Finally, Espinosa et al. [12] focus on peroneal tendon dislocation and give us a clinically oriented proposal for classification and choice of treatment.

\section{Compliance with ethical standards}

Conflict of interest Thomas Mittlmeier declares that he has no conflict of interest.

Ethical standards The authors complies with the ethical guidelines for authorship and publishing in the European Journal of Trauma and Emergency Surgery. This article does not contain any studies with human or animal subjects performed by the author.

\section{References}

1. Marx RC, Mizel MS. Specialty update. What's new in foot and ankle surgery? J Bone Joint Surg Am. 2015;97:862-8. 
2. Goost H, Wimmer DM, Barg A, Kouroush KM, Valderrabano V, Burger C. Fractures of the ankle joint. Dtsch Arztebl Int. 2014;111:377-88.

3. De Vries JS, Wijgman AJ, Sierevelt IN, Schaap GR. Long-term results of ankle fractures with a posterior malleolar fragment. J Foot Ankle Surg 2005;44:211-7.

4. Drijfhout van Hooff CC, Verhage SM, Hoogendoorn JM. Influence of fragment size and postoperative joint congruency on long-term outcome of posterior malleolar fractures. Foot Ankl Int. 2015;36:673-8.

5. Verhage SM, Schipper IB, Hoogendoom JM. Long-term functional and radiographic outcomes in 243 operated ankle fractures. J Foot Ankle Res. 2015;8:45.

6. Bartoníček J, Rammelt S, Tuček M, Naňka O. Posterior malleolar fractures of the ankle. Eur J Trauma Emerg Surg. doi:10.1007/ s00068-015-0560-6
7. Rammelt S, Obruba P. An update on the evaluation and treatment of syndesmotic injuries. Eur J Trauma Emerg Surg. doi:10.1007/ s00068-014-0466-8

8. Roth JA, Taylor WC, Whalen J. Peroneal tendon subluxation: the other lateral ankle injury. Br J Sports Med. 2010;44:1047-53.

9. Cho J, Kim JY, Song DG, Lee WC. Comparison of outcome after retinaculum repair with and without fibular groove deepening for recurrent dislocation oft he peroneal tendons. Foot Ankle Int. 2014;35:683-9.

10. Lötscher P, Lang TH, Zwicky L, Hintermann B, Knupp M. Osteoligamentous injuries of the medial ankle joint. Eur J Trauma Emerg Surg. doi:10.1007/s00068-015-0548-2

11. Mittlmeier T, Wichelhaus A. Subtalar joint instability. Eur J Trauma Emerg Surg. doi:10.1007/s00068-015-0588-7

12. Espinosa N, Maurer MA. Peroneal tendon dislocation. Eur $\mathbf{J}$ Trauma Emerg Surg. doi:10.1007/s00068-015-0590-0 